\title{
Perbandingan proxy pada linux dan windows untuk mempercepat browsing website
}

\author{
Dafwen Toresa \\ Program Studi Teknik Informatika Fakultas Ilmu Komputer Universitas Lancang Kuning \\ Jl. Yos Sudarso KM. 8 Rumbai, Pekanbaru, Riau, telp. 08117532015 \\ e-mail: dafwentoresa@gmail.com
}

\begin{abstract}
Abstrak
Pada saat ini sangat banyak organisasi, baik pendidikan, pemerintahan, maupun perusahaan swasta berusaha membatasi akses para pengguna ke internet dengan alasan bandwidth yang dimiliki mulai terasa lambat ketika para penggunanya mulai banyak yang melakukan browsing ke internet. Mempercepat akses browsing menjadi perhatian utama dengan memanfaatkan teknologi Proxy server. Penggunaan proxy server perlu mempertimbangkan sistem operasi pada server dan tool yang digunakan belum diketahui performansi terbaiknya pada sistem operasi apa. Untuk itu dirasa perlu untuk menganalisis performan Proxy server pada sistem operasi berbeda yaitu Sistem Operasi Linux dengan tools Squid dan Sistem Operasi Windows dengan tool Winroute. Kajian ini dilakukan untuk mengetahui perbandingan kecepatan browsing dari komputer pengguna (client). Browser yang digunakan di komputer pengguna adalah Mozilla Firefox. Penelitian ini menggunakan 2 komputer klien dengan pengujian masing-masingnya 5 kali pengujian pengaksesan/browsing web yang dituju melalui proxy server. Dari hasil pengujian yang dilakukan, diperoleh kesimpulan bahwa penerapan proxy server di sistem operasi linux dengan tools squid lebih cepat browsing dari klien menggunakan web browser yang sama dan komputer klien yang berbeda dari pada proxy server sistem operasi windows dengan tools winroute.
\end{abstract}

Kata kunci: Proxy, Bandwidth, Browsing, Squid, Winroute

\begin{abstract}
At this time very many organizations, both education, government, and private companies try to limit the access of users to the internet on the grounds that the bandwidth owned began to feel slow when the users began to do a lot of browsing to the internet. Speed up browsing access is a major concern by utilizing Proxy server technology. The use of proxy servers need to consider the operating system on the server and the tool used is not yet known the best performance on what operating system. For that it is necessary to analyze Performance Proxy server on different operating system that is Linux Operating System with Squid tools and Windows Operating System with Winroute tool. This study was conducted to determine the comparison of browsing speed of the user's computer (client). The browser used on the user's computer is Mozilla Firefox. This study uses two client computers with each test 5 times accessing web browsing / destination testing via proxy server. From the results of tests conducted, it can be concluded that the application of proxy server in linux operating system with squid tools faster browsing from client using the same web browser and client computer different from the proxy server windows operating system with winroute tools.
\end{abstract}

Keywords: Proxy Server, Linux, Windows, Squid, Winroute 


\section{Pendahuluan}

Perkembangan teknologi informasi berkembang dengan sangat cepat. Dalam perkembangan teknologi informasi tidak terlepas dari pembagian informasi dengan media jaringan komputer (Computer Networking). Terhubungnya sistem dan jaringan lokal dari suatu organisasi dengan jaringan global / lebih luas yang terhubung dengan internet dapat menimbulkan masalah baru yang cukup kompleks, beberapa diantaranya yaitu masalah keamanan, efesiensi bandwidth serta kecepatan akses browsing serta masih banyak permasalahan yang akan muncul dengan tergabungnya suatu sistem atau jaringan dengan jaringan Global / internet. Dengan terhubungnya kita dengan jaringan global / internetworking akan membuka peluang dari luar jaringan atau orang lain untuk masuk dapat mengakses sistim kita, begitu juga sebaliknya.

Untuk mempercepat browsing dalam suatu jaringan internet adalah dengan membangun sebuah Proxy server. Sistem operasi komputer yang banyak di gunakan saat ini adalah Linux yang merupakan sistem operasi Open Source yang saat ini berkembang dengan pesat dan Windows yang merupakan sistem operasi Close Source. Kedua sistem operasi tersebut dapat digunakan untuk membangun Proxy Server dengan menggunakan tools Squid untuk sistem operasi linux dan winroute untuk sistem operasi windows.

Tujuan yang ingin dicapai adalah melihat dan membandingkan Proxy dengan sistem operasi mana yang lebih cepat dalam membuka website (broswing) antara Proxy Linux menggunakan Squid dibandingkan atau Proxy Windows menggunakan winroute.

\section{Metodologi Penelitian}

Metodologi yang digunakan menyelesaikan penelitian ini adalah sebagai berikut:

a. Studi Literatur

Mengumpulkan dan memperlajari teori yang berhubungan dengan sistem operasi Microsoft Windows, Redhat 9 dan proxy servers menggunakan squid dan winroute serta pengimplementasian proxy server pada Windows dan Linux.

b. Analisis dan Perancangan

Melakukan analisis kecepatan browsing yang akan dilakukan pada komputer client yang mengakses situs dari server yang menggunakan squid pada linux dan winroute pada windows dan perancangan jaringan komputer client-server yang digunakan untuk pengujian.

c. Instalasi dan Konfigurasi

Melalukan implementasi dan konfigurasi server di komputer yang memenuhi spesifikasi minimum untuk server dengan sistem operasi Microsoft Windows dan Redhat 9. Setelah dilakukan implementasi dan konfigurasi server, dilakukan instalasi dan konfigurasi proxy server squid dan proxy server winroute. Untuk akses internet digunakan koneksi dari ISP yang terkoneksi kepada komputer server.

d. Percobaan dan Analisis hasil Percobaan

Setelah instalasi dan konfigurasi server, dilakukan beberapa kali percobaan untuk mengakses beberapa situs pada server yang menggunakan sistem operasi Linux dan Windows, dengan menggunakan browser Mozilla Firefox dari komputer klien.

Hasil percobaan dari masing-masing server dicatat berupa waktu lama pengaksesan untuk menampilkan situs yang diakses. Hasil tersebut diolah yang kemudian disimpulkan server dengan sistem operasi dan tools yang lebih baik digunakan jika menggunakan proxy server.

\subsection{Analisis Masalah Kasus dalam Membangun Proxy}

Masalah yang akan diteliti adalah bagaimana handalnya proxy server yang digunakan untuk meningkatkan kecepatan pengaksesan Internet pada dua server dengan sistem operasi dan 
tools yang berbeda. Load time proxy untuk menampilkan satu halaman utuh sebuah website merupakan nilai yang akan diperhatikan dan dicatat pada penelitian ini.

Load Time pengaksesan website adalah waktu yang dibutuhkan web browser pada client untuk menampilkan situs yang diakses dari server. Load time yang dicatat berupa waktu sampai selesainya situs yang diakses ditampilkan pada web browser klien.

\subsection{Perancangan}

Urutan kegiatan dibawah ini dilakukan tahap demi tahap agar tercapainya rancangan Proxy yang handal. Semua itu akan menjadi faktor penentu dalam mendesain dan mengimplementasikan fasilitas menghemat bandwidth dan mempercepat akses browsing. Adapun langkah-langkah tersebut adalah sebagai berikut:

Jaringan yang digunakan untuk pengujian adalah jaringan dengan jenis clientserver, dimana ada satu komputer yang bertindak sebagai server dan komputer yang terhubung dengannya sebagai klien. Untuk topologi jaringannya, kajian ini menggunakan topologi star dimana server dan klien akan dihubungkan oleh hub/switch (media penghubung), penelitian ini menggunakan dua klien. Untuk pelaksanaan kajian, diperlukan media pengujian. Media pengujian menggunakan dua server.

Bagian pada perancangan diuraikan sebagai berikut:

a. ISP dalah Vendor penyedia media untuk berkomunikasi dengan jaringan Internet.

b. Server merupakan komputer yang melayani setiap permintaan klien yang terhubung dalam jaringannya.

c. Hub/Switch merupakan penghubung antara komputer server dengan komputer klien.

d. Workstation (komputer klien) merupakan komputer yang meminta layanan ke server.

e. Kabel UTP (Unshielded Twisted Pair) straight yang digunakan untuk mengkoneksikan komputer klien dan server dengan memakai sambungan switch.

f. Rancangan IP Address untuk komputer klien dan server dibuat statik menggunakan $I P$ Address versi 4. IP Address yang digunakan yaitu kelas $C$ yang terdiri dari 24 bit untuk network ID dan sisanya 8 bit digunakan untuk host ID. IP address kelas $\mathrm{C}$ digunakan untuk jaringan ukuran kecil. Pada 3 bit pertama berikan angka 110 sehingga bit awal IP tersebut mulai dari $(192-223)$.

\subsection{Pengujian}

Situs yang diakses ditentukan dengan memperhatikan situs yang sering diakses oleh pengguna internet contohnya situs jejaring sosial, pendidikan, dan berita. Situs yang akan diakses dan dicatat response time pengaksesannya sebagai berikut:
a. http://www.kompas.com/
b. http://www.alibaba.co.id/
c. http://www.detik.com/
d. http://www.amazone.com/

Sebelum melakukan pengujian, perlu ditentukan tahapan yang dilakukan secara sistematis. Pada Proxy Windows dan Proxy Linux dilakukan tahapan yang sama. Tahapan yang dilakukan ditampilkan pada gambar diagram alir berikut. 


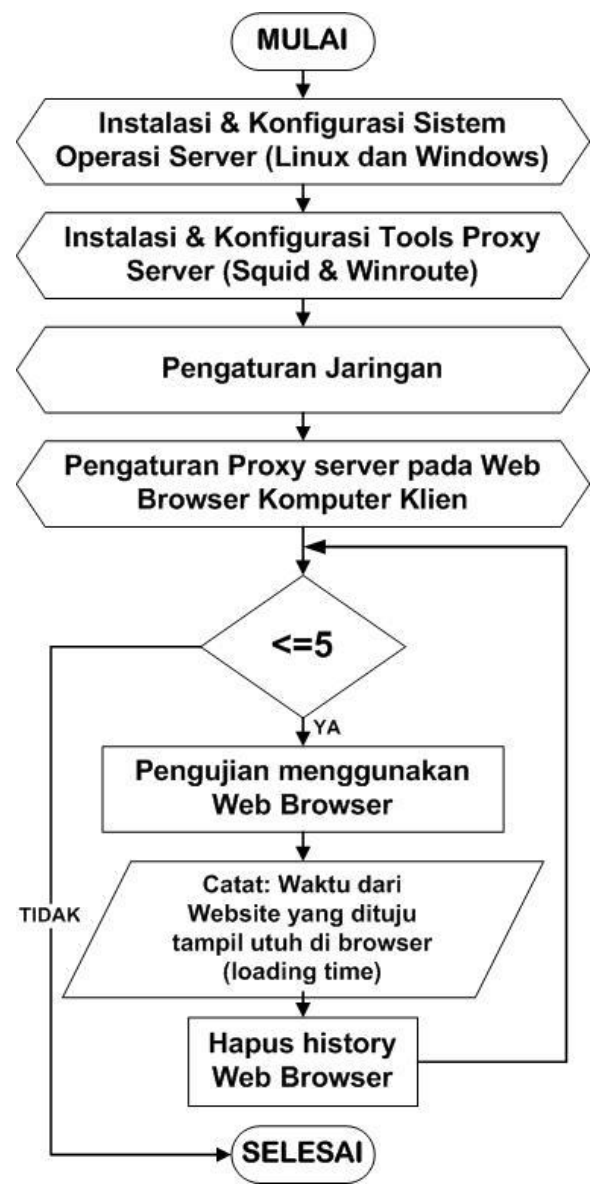

Gambar 1

Diagram Alir Tahapan Pengujian

Sebelum melakukan pengujian, dilakukan persiapan pada komputer server yaitu:

a. Instalasi dan Konfigurasi Server meliputi setting IP Address server.

b. Instalasi dan konfigurasi squid pada proxy server sistem operasi Linux dan winroute pada proxy server

Tahapan yang dilakukan pada komputer klien sebagai berikut.

a. Pengaturan network connection komputer server

b. Konfigurasi proxy server pada web browser yang akan digunakan

c. Hubungkan server dengan komputer klien seperti gambar rancangan jaringan.

d. Lakukan percobaan pengaksesan situs yang sudah ditentukan.

e. Catat waktu yang dibutuhkan untuk menampilkan masing-masing situs yang diakses pada komputer client. Waktu yang dicatat adalah waktu yang ditunjukkan pada browser.

f. Hapus history pengaksesan pada browser di komputer klien.

g. Kembali ke langkah d, e, dan f. Jika sudah dilakukan 5 kali pengujian selesai untuk kelima situs yang sudah ditentukan sebelumnya.

Hasil pencatat response time pada pengujian yang akan diolah untuk mendapatkan kesimpulan dari kajian. 


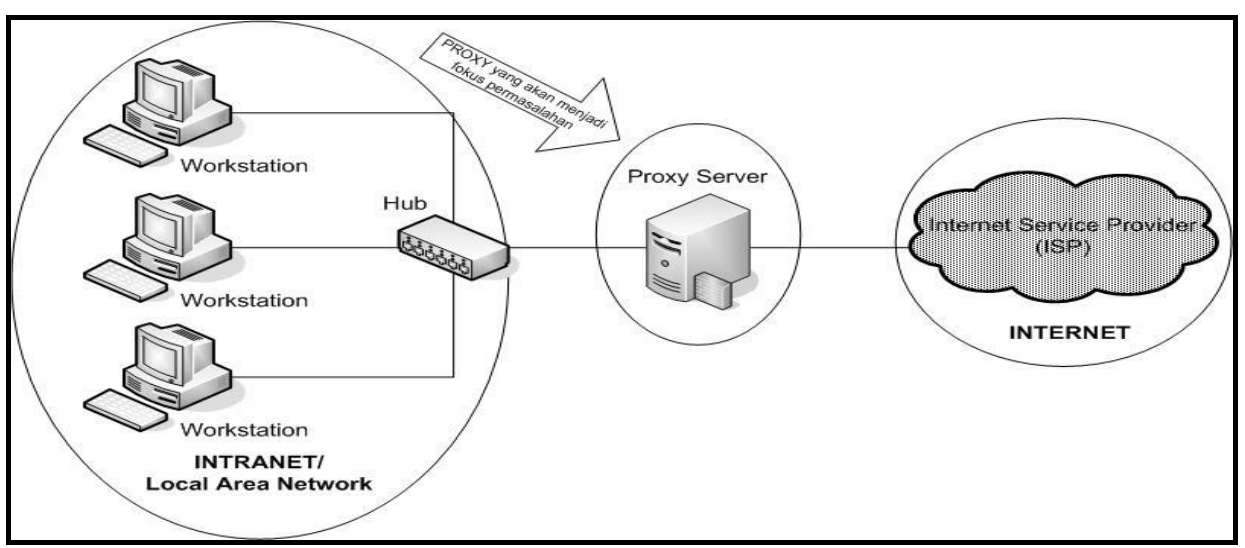

Gambar 2

Rancangan Jaringan

\section{Hasil dan Pembahasan}

\subsection{Pencatatan kecepatan waktu pada Browser}

Untuk mengetahui respon time/load time pengaksesan situs diambil dari waktu yang ditunjukkan pada browser Mozilla Firefox sampai selesai menampilkan seluruh halaman situs, dilakukan dengan tahapan sebagai berikut :

a. Buka browser Mozilla Firefox

b. Akses sebuah website untuk menghitung load time https://tools.pingdom.com

c. Pada bagian enter the URL ketik website yang akan di hitung load time-nya dan hasilnya akan seperti gambar berikut.

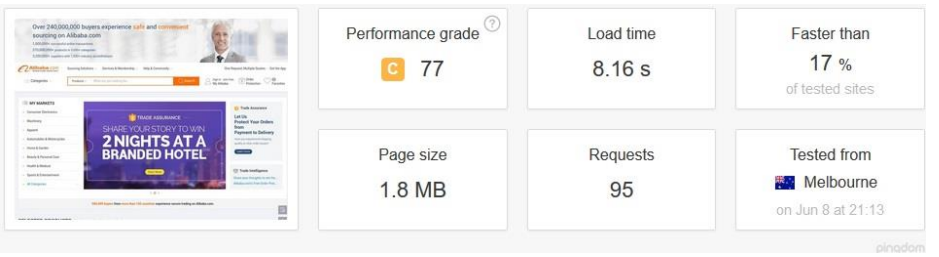

\subsection{Hasil Pengujian Load Time}

Pengujian dilakukan pada komputer klien. Sebelum melakukan pengujian, perlu dilakukan pengaturan IP Addres Komputer klien. Pengaturannya dilakukan dengan tahapan sebagai berikut :

a. Klik tombol Start $\rightarrow$ Control Panel $\rightarrow$ Network Connections $\rightarrow$ Local Area Connection

b. Pada Tab General dalam dialog tersebut cari Internet Protocol (TCP/IP) dan klik tombol Properties.

c. Untuk pengaturan IP Address dinamis Pilihlah tombol radio button Obtain an IPAddress automatically dan Obtain DNS server address automatically. Untuk pengaturan IP Address statis Pilihlah tombol radio button Use the following IP address kemudian isikan bagian IP Address dengan alamat komputer sesuai dengan server yang digunakan, pada bagian Subnet mask diisi dengan 255.255.255.0 dan pada bagian Default Gateway isikan dengan IP Address dari komputer yang bertindak sebagai server.

d. Untuk mengakhiri dan menyimpan perubahan yang dilakukan, klik tombol OK kemudian klik tombol Close dan jika muncul dialog konfirmasi untuk merestrart komputer maka pilihlah restart komputer. 
Setelah pengaturan IP Address dilakukan, maka dilanjutkan dengan pengaturan HTTP Proxy menjadi IP Address server dengan port 8080 pada browser klien, langkahnya sebagai berikut:

a. Buka browser Mozilla Firefox pada komputer klien. Pilih menu Tools dan sub menu Option $\rightarrow$ pilih Advance $\rightarrow$ pilih Network $\rightarrow$ klik tombol Setting.

b. Pilih Manual proxy configuration, pada bagian HTTP Proxy, ketikkan IP Address server dan port server 8080 dan klik OK untuk mengakhiri konfigurasi Proxy pada Mozilla Firefox.

Pengujian dilakukan sebanyak 5 kali dengan masing-masing Proxy Server. Rata-rata load time dihitung dengan cara menjumlahkan keseluruhan response time dibagi dengan jumlah percobaan yang dilakukan, dirumuskan sebagai berikut :

rata-rata load time $=$ jumlah load time jumlah percobaan

\subsubsection{Hasil Pengujian Load Time Proxy Linux}

Hasil kecepatan browing / load time sampai menampilkan utuh halaman website (dalam satuan detik) yang dilakukan dari komputer klien pada server Linux diuraikan pada tabel 1 berikut.

Tabel 1.

Kecepatan Browsing menggunakan Proxy Windows

\begin{tabular}{|l|c|c|c|c|r|c|}
\hline \multirow{2}{*}{ Website } & \multicolumn{5}{|c|}{ Test ke - } & \multirow{2}{*}{$\begin{array}{c}\text { Rata-rata } \\
\text { Loading time }\end{array}$} \\
\cline { 2 - 6 } & $\mathbf{1}$ & $\mathbf{2}$ & $\mathbf{3}$ & $\mathbf{4}$ & $\mathbf{5}$ & $\mathbf{4}$ \\
\hline http://www.kompas.com/ & 4,7 & 4,5 & 4,1 & 4,6 & $\mathbf{5}$ & 4,6 \\
\hline http://www.alibaba.co.id/ & 7,6 & 7,2 & 7,2 & 7,5 & 7,1 & 7,3 \\
\hline http://www.detik.com/ & 5,7 & 5,7 & 5,4 & 5,6 & 5,3 & 5,5 \\
\hline http://www.amazone.com/ & 5,8 & 5,6 & 5,7 & 5,8 & 5,2 & 5,6 \\
\hline
\end{tabular}

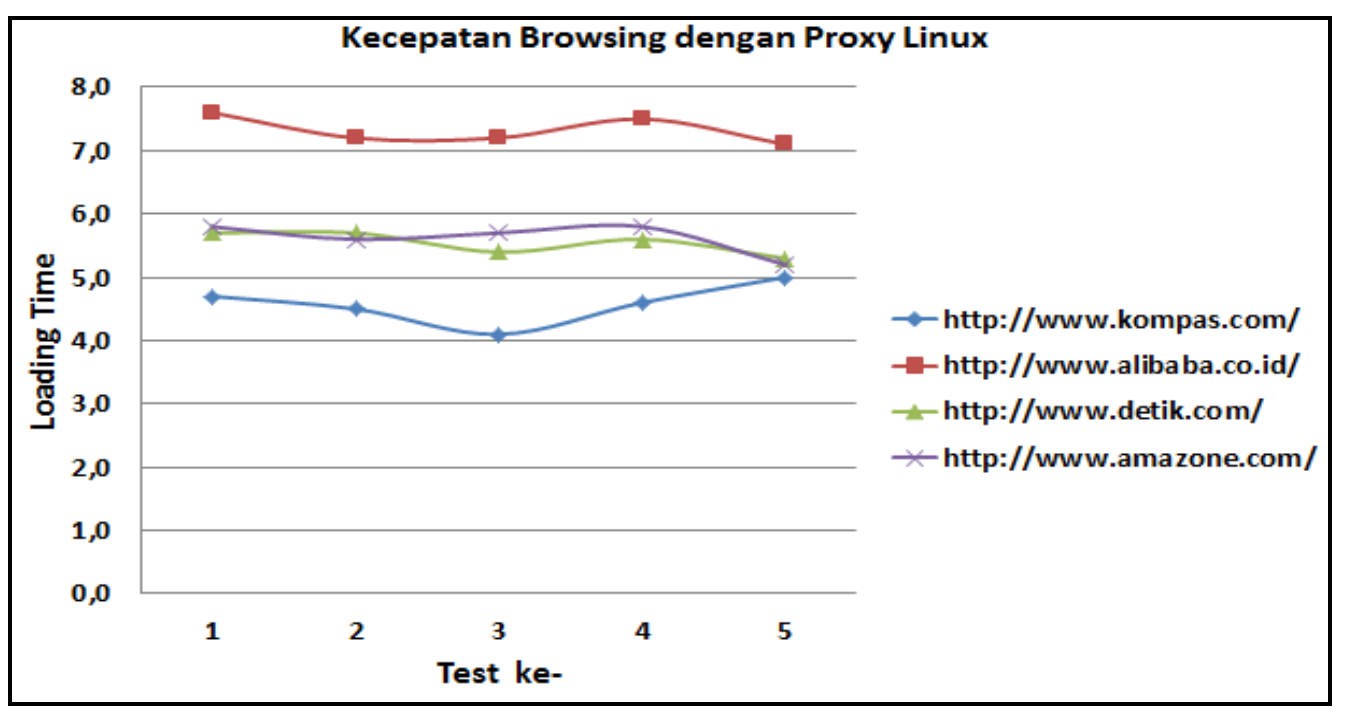




\subsubsection{Hasil Pengujian Load Time Proxy Windows}

Hasil kecepatan browing / loading time sampai menampilkan utuh halaman website (dalam detik) yang dilakukan dari komputer klien pada server Windows diuraikan pada tabel 2 berikut.

Tabel 2.

Kecepatan Browsing menggunakan Proxy Windows

\begin{tabular}{|l|r|r|r|r|c|c|}
\hline \multirow{2}{*}{ Website } & \multicolumn{4}{|c|}{ Test ke- } & Rata-rata \\
\cline { 2 - 6 } & 1 & 2 & 3 & 4 & 5 & Loading time \\
\hline http://www.kompas.com/ & 5,9 & 6 & 5,5 & 5,4 & 5,7 & 5,7 \\
\hline http://www.alibaba.co.id/ & 8,8 & 7,8 & 8,6 & 8,5 & 8,8 & 8,5 \\
\hline http://www.detik.com/ & 6,7 & 6 & 6,7 & 6,2 & 6,8 & 6,5 \\
\hline http://www.amazone.com/ & 6,5 & 6,1 & 6,4 & 6,3 & 6,6 & 6,4 \\
\hline
\end{tabular}

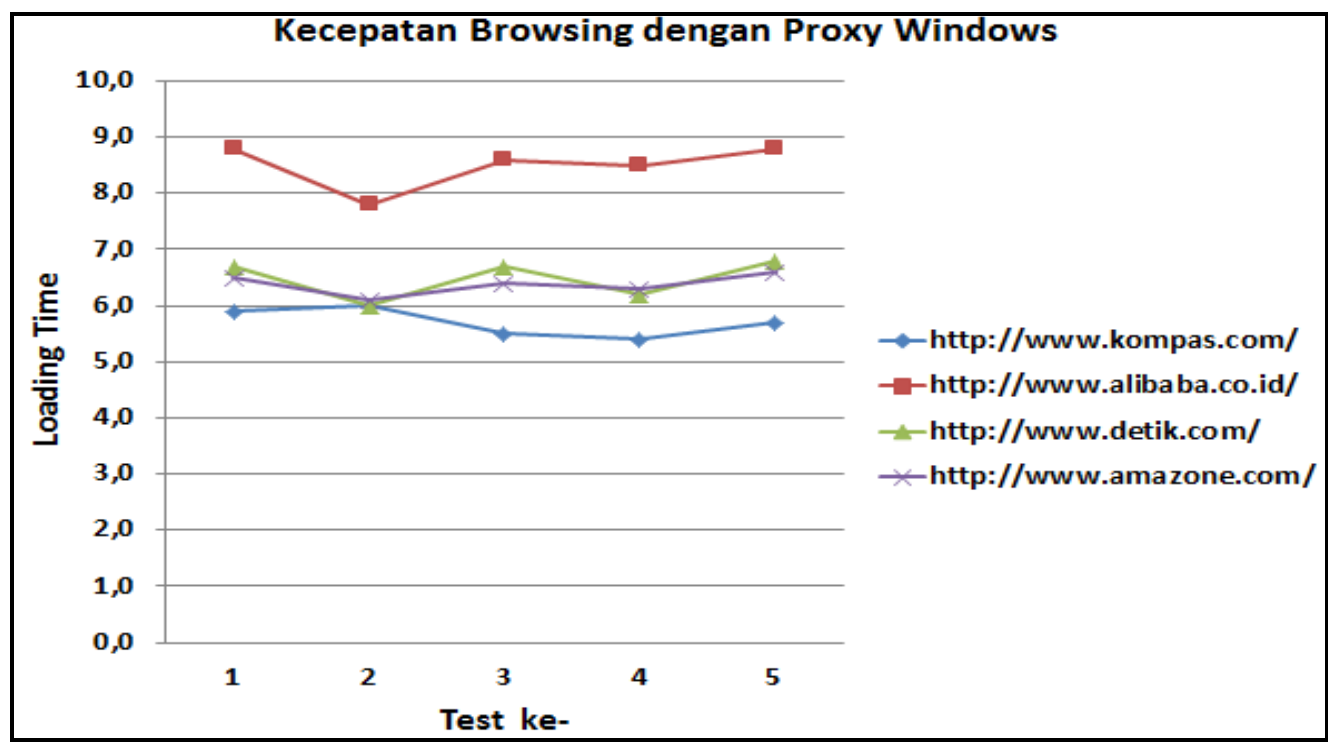

\section{Kesimpulan}

Berdasarkan hasil analisis terhadap hasil uji, maka dapat disimpulkan beberapa hal, yaitu:

1. Penggunaan proxy server bertujuan untuk meningkatkan kecepatan dalam mengakses website.

2. Rata-rata kecepatan browsing website paling kecil adalah melalui proxy linux dengan squid-nya yaitu: 4,6 detik; 7,3 detik; 5,5 detik; 5,6 detik.

3. Sementara proxy windows dengan winroute-nya rata-rata kecepatan browsing lebih tinggi dari proxy linux, yaitu: 5,7 detik; 8,5 detik; 6;5 detik dan 6,4 detik. 


\section{Saran} adalah:

Setelah melakukan kajian, beberapa hal yang disaranjan untuk penelitian selanjutnya

1. Kecepatan browsing untuk membuka website dilakukan dari komputer klien dengan menggunakan browser Mozilla Firefox.

2. Untuk penelitian selanjutnya dapat dilakukan dengan menggunakan lebih dari satu web browser untuk membuka website yang sama.

\section{Daftar Pustaka}

[1] Yuhandri, 2013 Penerapan Proxy Server Dengan Menggunakan Sistem Operasi Linux Pada Hotspot Universitas Putra Indonesia "YPTK" Padang. Padang: Jurnal Media Processor. Vol 8, No.3, Oktober 2013

[2] Gina Akmalia, Evlyna Tunggawan, Kevin Sungiardi, Alfian Lazuardi, 2013. Distributed Proxy Server dengan Squid pada Sistem Operasi Windows 7. Jurnal Media ULTIMA InfoSys, Vol. IV, No.2, Desember 2013

[3] Mochamad Hamdani, Nana Suarna, Yudhistira Arue Wijaya, Desember 2013. Optimalisasi Jaringan dengan menggunakan Squid Sebagai Proxy Server Pada Windows XP. Jurnal Online ICT SMIK IKMI Cirebon Vol. 10 - Desember 2013

[4] Umeshchandra, T. K., Ramjibhai, P. C., "Improve Squid Proxy's Performance Using New Cache Replacement Architecture," IJMIE, vol. 2, no. 7, hal. 418-431, Juli 2012.

[5] Tsui, K.C., Kaiser, M.J., Liu, J., "Distributed Proxy Server Management: A SelfOrganized Approach," Kluwer Academic Publisher, hal. 2, Sept. 2013.

[6] Maryanto Dodi. Optimasi Akses Internet dengan SQUID.Jakata: PT. Elex Media Komputindo.2001

[7] Cartealy, Imam. 2013. Linux Networking Ubuntu, Kubuntu, Debian, DLL, Jakarta: Jasakom.

[8] Winarno, edy, ali Zaki, SmitDev Community. 2014. Membuat Jaringan Komputer di Windows dan Linux. Jakarta: PT. Elex Media Komputindo

[9] Raharjo Budi. Keamanan Sistem Informasi Berbasis Internet. (2002). PT Insan Indonesia-Bandung dan PT. INDOCISC-Jakarta

[10] Sanjaya Ridwan. Trik Mengelola Kuato Internet Bersama dengan SQUID. Jakarta : PT. Elex Media Komputindo.2005.

[11] Kulbir Saini. 2011. Squid Proxy Server 3.1 Beginner's Guide. Birmingham: Packt Publishing Ltd. Majid Nur Kholis.

[12] Harianto Bambang. Buku Teks Ilmu Komputer Sistem Operasi Edisi Kedua. Bandung : Informatika. 1999. 